\title{
Expression of the Kv3.1 Potassium Channel in the Avian Auditory Brainstem
}

\author{
Suchitra Parameshwaran, ${ }^{1}$ Catherine E. Carr, ${ }^{1}$ and Teresa M. Perney ${ }^{2}$ \\ ${ }_{1}^{1}$ Program in Neurobiology and Cognitive Science, Department of Biology, University of Maryland, College Park, Maryland \\ 20742, and ${ }^{2}$ Center for Molecular and Behavioral Neuroscience, Rutgers University, Newark, New Jersey 07012
}

The Shaw-like potassium channel Kv3.1, a delayed rectifier with a high threshold of activation, is expressed in the time coding nuclei of the bird auditory brainstem. In both barn owls and chickens, Kv3.1 mRNA was expressed in the cochlear nucleus magnocellularis (NM) and the nucleus laminaris (NL). Western blot analysis showed that an antibody raised against the synthetic peptide sequence of rat Kv3.1 (rKv3.1) specifically recognized the same $92 \mathrm{kDa}$ protein bands in both rat and chicken synaptosomal preparations. Immunohistochemical analyses using this anti-rKv3.1 antibody revealed a prominent gradient in Kv3.1 immunoreactivity along the tonotopic axis of the barn owl NM and NL and a less prominent gradient in the chicken. The precise localization of the Kv3.1 immunoproduct was resolved by electron microscopy. In both the owl and the chicken, Kv3.1 was targeted postsynaptically in NM and NL. The major difference in localization of Kv3.1 protein between the two birds was the expression of Kv3.1 in the NM axons and terminals in the region of the barn owl NL. This location of Kv3.1 channels supports its postulated function in reducing the width of action potentials as they invade the presynaptic terminal. The presynaptic localization may be a specialization for enabling neurons in owl NM to transmit high-frequency temporal information with little jitter.

Key words: barn owl; chicken; potassium channel; Kv3.1; cochlear nuclei; tonotopic gradient
We have compared the distribution of a high-threshold potassium channel in the auditory system of the chicken and the barn owl. Chickens are auditory generalists, with range similar to most other birds (up to $\sim 4 \mathrm{kHz}$; Gray and Rubel 1985), whereas barn owls are auditory specialists with an extended frequency range (up to $12 \mathrm{kHz}$; Konishi, 1973). The barn owl's ability to localize sounds is also far superior to birds like the quail and the pigeon (Klump, 2000). We have used comparisons between barn owls and chickens to find organizational differences that might underlie the owl's superior sound localization ability.

Cues for azimuthal sound localization are derived from the analysis of interaural time differences (ITDs). ITDs are detected in a circuit composed of the auditory nerve, the cochlear nucleus magnocellularis (NM), and the nucleus laminaris (NL) (Parks and Rubel 1975; Overholt et al., 1992; Carr and Konishi, 1990). The projection from NM to NL resembles the Jeffress model circuit for the detection of time differences in that the NM axons act as delay lines, and NL neurons as coincidence detectors (Jeffress, 1948; Carr and Konishi, 1990; Overholt et al., 1992). Phaselocked spikes encode the timing of the acoustic stimulus and form the basis for the neural computation of ITDs in both birds and mammals (Rose et al., 1967; Sullivan and Konishi, 1984).

Several specializations have been identified that allow preservation of temporal information in the ITD circuit (for review, see Oertel, 1999; Trussell, 1999). The end bulbs of Held provide a

Received June 5, 2000; revised Oct. 18, 2000; accepted Oct. 30, 2000.

This work was supported by National Institutes of Health Grants DC00436 (C.E.C.) and DC02728 (T.M.P.). Drs. C. Köppl and R. Code provided helpful discussion. We are grateful to Tim Maugel and Jan Endlich for technical assistance and advice with electron microscopy and to Daphne Soares for her help with figures.

Correspondence should be addressed to Suchitra Parameshwaran, Department of Biology, University of Maryland, College Park, MD 20742-4415. E-mail: suchitra@wam.umd.edu.

Copyright (C) 2001 Society for Neuroscience $0270-6474 / 01 / 210485-10 \$ 15.00 / 0$ morphological substrate for secure synapses between the auditory nerve and the neurons of NM (Jhaveri and Morest 1982; Carr and Boudreau, 1991). Second, AMPA receptors containing the GluR $4_{\text {flop }}$ subunit contribute to the rapid response of the postsynaptic cell by virtue of their rapid desensitization kinetics (Raman and Trussell, 1992; Raman et al., 1994; Ravindranathan et al., 1996, 1997; Levin et al., 1997). Last, a low-threshold potassium conductance, whose pharmacological and physiological properties approximately correspond to clones of the Kv1 subfamily, decreases the effective time constant of the membrane and prevents temporal summation (Oertel, 1983; Manis and Marx, 1991; Reyes et al., 1994; Brew and Forsythe, 1995; Rathouz and Trussell, 1998).

Time-coding neurons also display a high-threshold potassium conductance that may be mediated by members of the Kv3 subfamily of voltage-gated potassium channels (Manis and Marx, 1991; Brew and Forsythe, 1995; Wang et al., 1998a; Rathouz and Trussell, 1998). The mammalian Kv3 subfamily consists of four members (Kv3.1, 3.2, 3.3, and 3.4), each generating multiple gene products by alternative splicing. All channels formed by Kv3 subunits activate rapidly at potentials positive to $-10 \mathrm{mV}$ (for review, see Rudy et al., 1999). In fast-spiking neurons, the current associated with Kv3.1 allows the rapid repolarization necessary for high-frequency firing (Massengill et al., 1997; Martina et al., 1998; Wang et al., 1998a; Erisir et al., 1999; Hernández-Pineda et al., 1999). Computer simulations have suggested that the Kv3.1 conductance also improves postsynaptic temporal coding precision (Perney and Kaczmarek, 1997; Wang et al., 1998a). In an attempt to define the molecular substrates for the exemplary phase-locking capability of auditory neurons in the owl, we have compared the anatomical distribution of Kv3.1 in the time-coding nuclei of owls and chickens. 


\section{MATERIALS AND METHODS}

All methods were approved by the University of Maryland animal care and use committee and conform to National Institutes of Health guidelines.

In situ hybridization. Three owls and three chickens were anesthetized with $50 \mathrm{mg} / \mathrm{kg}$ sodium pentobarbital and then decapitated. The brains were immediately removed and frozen in powdered dry ice. Twenty-five micrometer sections were cut on a cryostat, thaw-mounted onto salinized slides (Sigma, St. Louis, MO), and dried at room temperature for 6-8 hr. The slides were then stored desiccated at $-20^{\circ} \mathrm{C}$ until use. Digoxigenin (Dig)-labeled RNA probes were synthesized by in vitro transcription using the Dig RNA labeling kit (Roche Molecular Biochemicals, Indianapolis, IA) following manufacturer's protocol. Template for the Kv3.1 probes was prepared by subcloning the whole coding region of the rat Kv3.1b cDNA (Luneau et al., 1991) into Bluescript SK plasmid (Stratagene, La Jolla, CA) at the EcoRI and HindIII restriction sites and then linearizing this plasmid with $P v u \mathrm{II}$ or NaeI for antisense and sense probes, respectively. Linearized fragments separated on agarose gels were purified using glass milk (Gene Clean kit; Bio101, Vista, CA). The synthesized Dig-labeled RNA was precipitated with $0.1 \mathrm{M} \mathrm{Na}$ acetate, $\mathrm{pH}$ 5.2 , and resuspended in RNase-free water. Probe concentration was determined by comparing labeled probe to a known standard, as described in the Roche protocol.

For in situ hybridization, sections were post-fixed in $4 \%$ paraformaldehyde for $5 \mathrm{~min}$, pretreated with acetic anhydride and triethanolamine, defatted in grades of alcohol and chloroform, and then prehybridized in $5 \times$ SSC, $50 \%$ deionized formamide, $5 \times$ Denhardt's solution, and 250 $\mu \mathrm{g} / \mathrm{ml}$ yeast tRNA at $47^{\circ} \mathrm{C}$. The sections were then incubated in a humid chamber with probe reconstituted in prehybridization solution to a concentration of $6 \mu \mathrm{g} / \mu \mathrm{l}$ at $47^{\circ} \mathrm{C}$ overnight. Brain sections from rats were treated similarly and acted as positive controls. After hybridization, nondigested probe was degraded by a $30 \mathrm{~min}$ incubation in $100 \mu \mathrm{g} / \mathrm{ml}$ RNase A solution. Sections were then extensively washed with SSC solution with increasing stringency at $42^{\circ} \mathrm{C}$. Hybridized probes were detected using the Dig nucleic acid detection kit (Roche Molecular Biochemicals) following manufacturer's instructions.

Antibodies and immunoblot analysis. Antibodies to Kv3.1b used in these studies were characterized and purified as described elsewhere (Perney and Kaczmarek, 1997). The antibodies against the synaptic vesicle protein SV2 were a gift from Kathleen Buckley (Buckley and Kelly, 1985). For immunoblot analysis, synaptosomes were prepared from rat and chicken brain as follows. Briefly, $1.5 \mathrm{gm}$ of brain tissue was homogenized with 10 strokes of a Dounce homogenizer in $15 \mathrm{ml}$ of buffer containing $0.3 \mathrm{~m}$ sucrose, $10 \mathrm{~mm}$ sodium phosphate, $\mathrm{pH} 7.4,0.5 \mathrm{~m}$ EDTA, and a cocktail of protease inhibitors (in $\mu \mathrm{g} / \mathrm{ml}: 20$ phenylmethylsulfonyl fluoride, 1 leupeptin, 1 aprotinin, and 1 pepstatin A). Homogenates were centrifuged at $2000 \times g$ for $10 \mathrm{~min}$ to remove nuclei and debris. The supernatant was collected and centrifuged at 45,000 $\times g$ for $45 \mathrm{~min}$, and the resultant pellet was resuspended in $15 \mathrm{ml}$ of low sucrose buffer $(25$ mM Tris, $\mathrm{pH} 7.4,1 \mathrm{~mm}$ EDTA and added protease inhibitors) by several passages through a 23 gauge needle. The resuspended pellet was centrifuged at $8000 \times g$ to remove mitochondria, and then the collected supernatant was centrifuged at $45,000 \times g$ for $45 \mathrm{~min}$. The pellet was resuspended in $3 \mathrm{ml}$ of low sucrose buffer, and the protein concentration was determined using the BCA method (Pierce, Rockford, IL).

For immunoblots, $50 \mu \mathrm{g}$ of membrane protein was added to reducing sample buffer, boiled for $20 \mathrm{~min}$, and electrophoresed on 9\% SDS-PAGE gels. Protein was transferred to nitrocellulose membranes in Tris-glycine buffer with $0.1 \%$ SDS by rapid transfer $(100 \mathrm{~V})$ for $1 \mathrm{hr}$ at $4^{\circ} \mathrm{C}$. Transfer of proteins was confirmed by Ponceau S (Sigma) staining. The blots were blocked with $4 \%$ nonfat dry milk in TBST $(0.1 \mathrm{~m}$ Tris-buffered saline and $0.05 \%$ Tween 20) for $2 \mathrm{hr}$ and then incubated with affinity-purified antibodies $(1-2 \mu \mathrm{g} / \mathrm{ml})$ for $2 \mathrm{hr}$ at room temperature. In some cases, the antisera was preabsorbed with $50 \mu \mathrm{M}$ of synthetic peptide for $30 \mathrm{~min}$. Blots were then washed in 4\% milk-TBST and incubated with 1:5000 dilution of HRP-conjugated goat anti-rabbit IgG (Jackson Laboratories, West Grove, PA) in TBST for $2 \mathrm{hr}$. After washing, bound antibody was detected by enhanced chemiluminescence reaction (Super Signal kit; Pierce) following manufacturer's instructions.

Immunohistochemistry. Three adult owls and three chickens (15-17 d after hatching) were used. The birds were deeply anesthetized with sodium pentobarbital $(50 \mathrm{mg} / \mathrm{kg}$, i.m.) and perfused through the heart with $25-100 \mathrm{ml}$ of $0.1 \mathrm{M}$ PBS, $\mathrm{pH} 7.2$, followed by $100-200 \mathrm{ml} 4 \%$ electron microscopy (EM) grade paraformaldehyde (Electron Microscopy Sciences, Fort Washington, PA) in PBS. The brains were dissected out, post-fixed for $1 \mathrm{hr}$ in $4 \%$ paraformaldehyde, and then sunk overnight in $15 \%$ sucrose-PBS. Fifty micrometer sections were cut on a freezing microtome and collected into PBS. Endogenous peroxidase activity was quenched by incubating sections for $10 \mathrm{~min}$ in $1 \%$ hydrogen peroxide and $50 \%$ methanol. After washing with PBS, sections were blocked for $1 \mathrm{hr}$ in staining medium (DMEM, 10\% fetal bovine serum, 1\% Triton X-100, and $0.02 \% \mathrm{Na}$ azide; Life Technologies, Gaithersburg, MD; ) and then incubated overnight at room temperature with antibody $(\sim 2 \mu \mathrm{g} / \mathrm{ml} \mathrm{Kv} 3.1$ or 1:1000 of SV2). After washing in PBS, the sections were incubated in a 1:400 dilution of HRP-conjugated goat anti-rabbit IgG (Vector Laboratories, Burlingame, CA) in PBS for $4 \mathrm{hr}$ and then washed again. Reaction product was visualized with diaminobenzidine $(0.03 \%)$ and hydrogen peroxide $(0.003 \%)$, intensified with $\mathrm{NiSO}_{4}(0.2 \%)$.

Preembedding immunoelectron microscopy. Three $5 \mathrm{~d}$ posthatch chicks and two adult owls were perfused transcardially with PBS followed by fixative as described above. The fixative was cold 4\% EM grade paraformaldehyde in $0.1 \mathrm{M}$ phosphate buffer, $\mathrm{pH} 7.2-7.3$, with $0.05 \%$ glutaraldehyde. Brains were removed, post-fixed for $1 \mathrm{hr}$, and sectioned with a vibratome at $50 \mu \mathrm{m}$. The sections were infiltrated with $15 \%$ sucrose in $5 \%$ glycerol-PBS and then subjected to three rounds of freezing with liquid nitrogen and thawing in a room temperature water bath. Sections were washed in PBS, then blocked for $1 \mathrm{hr}$ in $10 \%$ fetal bovine serum in DMEM followed by addition of primary antibody $(0.5 \mu \mathrm{g} / \mathrm{ml})$, overnight at room temperature. After washing, staining was visualized using avidin-biotin-peroxidase (Vectastain Elite kit; Vector Laboratories) and 3,3-diaminobenzidine tetrahydrochloride following the manufacturers' protocol. Sections used for EM were fixed in $1 \%$ osmium tetroxide, washed with $0.05 \mathrm{M}$ maleate buffer, $\mathrm{pH}$ 5.2, dehydrated, and embedded in Epon araldite 502 (Electron Microscopy Sciences). Thin sections were cut on an ultramicrotome (Reichert Jung) and examined after staining with uranyl acetate in a Zeiss transmission electron microscope.

Data analysis. Immunopositive neurons were characterized by brown reaction product while the in situ hybridization reaction product was purple. We described the Kv3.1 staining patterns on an arbitrary scale of intensity where intense $>$ dark $>$ moderate $>$ light. The gradients in Kv3.1 immunoreactivity were quantified using NIH image (Scion version 1.62) in combination with the Scion LG3 frame grabber and an Olympus video camera (OLY 750). The relative optical density (OD) of cells was measured in selected sections. For chicken and barn owl NM, the outline of each cell body was traced in NIH Image, and the relative OD of each stained cell in the selected area was measured. Because staining in chicken NL was not homogeneous, we measured OD values from the proximal region of the dorsal dendritic tufts. For the barn owl, we measured OD within each transverse section along the tonotopic axis, from medial to lateral. NL was divided into 0.5 -mm-long regions (see Fig. $6 B$, insert). In both chicken and barn owl, 10 nonoverlapping areas $(80 \times$ $80 \mu \mathrm{m})$ were sampled within each region.

\section{RESULTS}

We used both in situ hybridization and immunocytochemistry to examine Kv3.1 expression in the avian auditory system. We have described our results with reference to existing physiological and anatomical studies. In both owl and chick, NM neurons receive endbulb terminals from the auditory nerve and project bilaterally to NL (Fig. 1; Rubel and Parks, 1988; Carr and Konishi, 1990). The cells in NM and NL are arranged tonotopically (Rubel and Parks, 1975; Takahashi and Konishi, 1988). High best frequencies (BFs) are represented rostromedially, whereas low BFs are represented caudolaterally. Intermediate frequencies are mapped across the mediolateral extent of the nucleus.

\section{The Kv3.1 antibody recognizes a 92 kDa epitope in chicken}

Alternative splicing of the Kv3.1 gene gives rise to two isoforms that differ only at their $\mathrm{C}$ termini. The longer splice variant, $\mathrm{Kv} 3.1 \mathrm{~b}$, is the predominant isoform expressed in the adult brain (Perney et al., 1992). The antibody used in our studies was raised against a peptide corresponding to the $\mathrm{C}$ terminus of rat Kv3.1b (Perney et al., 1992). Immunoblot analysis of rat and chicken brain membranes revealed that this antibody also recognized the chicken Kv3.1 protein. A single band migrating at an estimated 

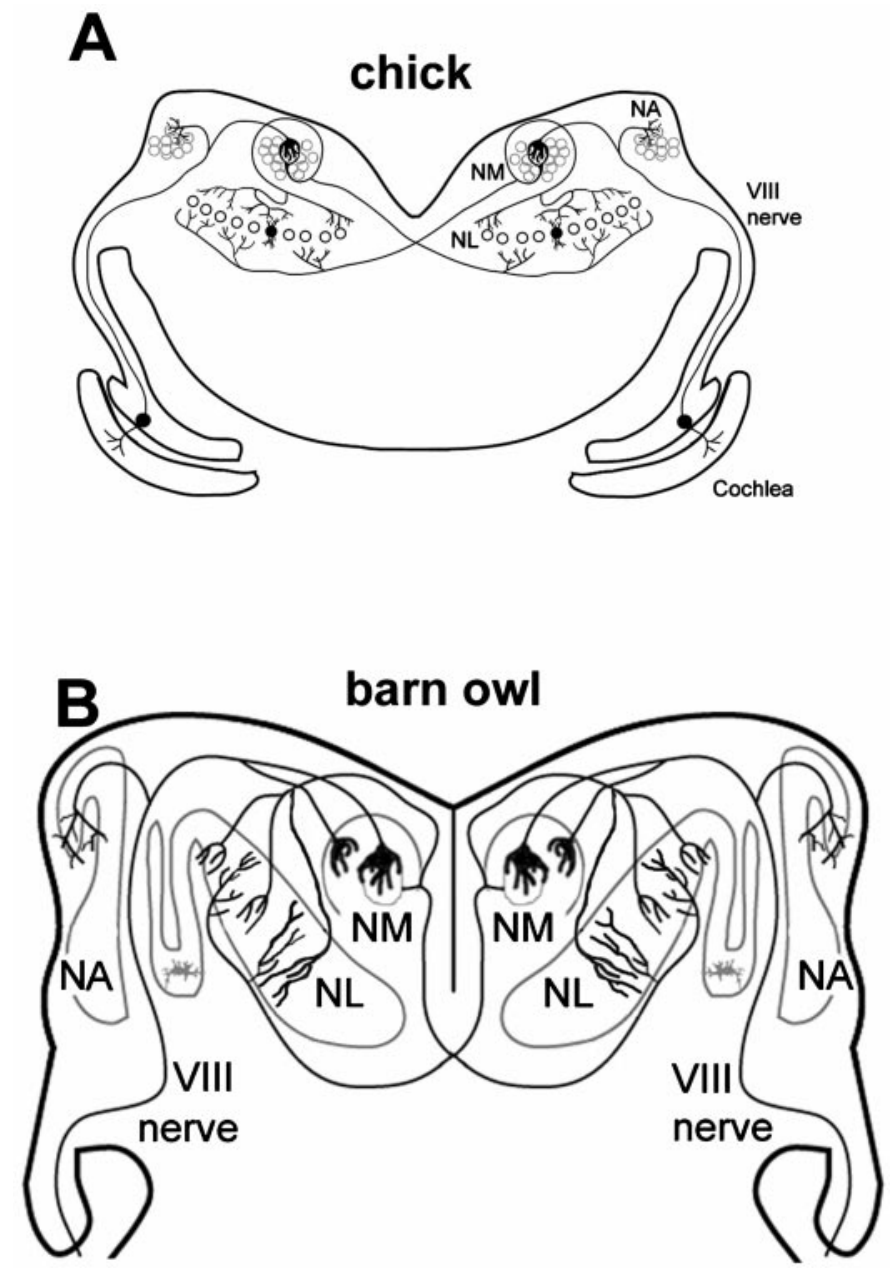

Figure 1. Schematic of a coronal section through the brainstem of chicken $(A)$ and owl $(B)$. The medial branch of the VIIIth nerve innervates NM. NL receives bilateral projections from NM. $A$, Modified from Rubel and Parks (1988).

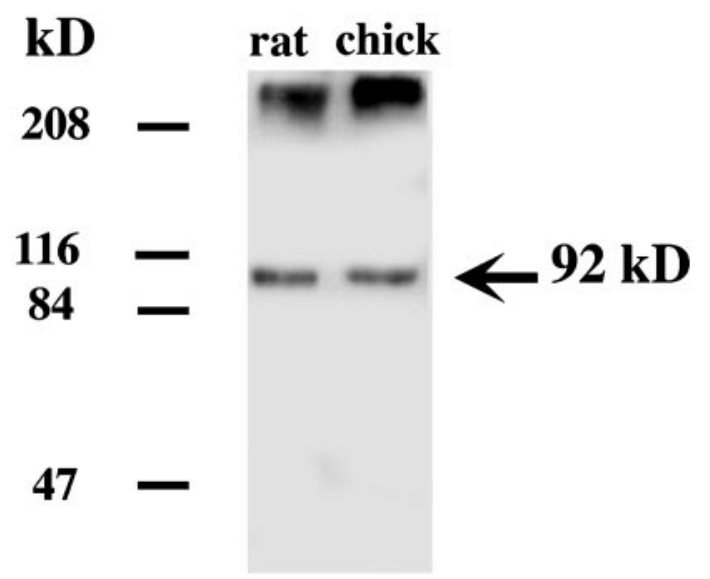

Figure 2. Western blot using the rat Kv3.1 antibody. The $92 \mathrm{kDa}$ bands correspond to the Kv3.1 protein in rat and chicken synaptosomal membrane preparations. The horizontal bars indicate the apparent molecular weights of prestained protein standard.

molecular weight of $92 \mathrm{kDa}$ was seen in both cases (Fig. 2). Another band detected at the interface between the stacking and resolving gels probably corresponded to multimers of Kv3.1 mi- grating at a slow rate. A similar high molecular weight band has been observed in Western blots published by other laboratories (Hernández-Pineda et al., 1999). No bands were detected when the antisera were preincubated with $50 \mu \mathrm{M}$ of the antigenic peptide (data not shown). These results demonstrate that the antibody used specifically recognizes the avian Kv3.1 protein and that positive immunoreactivity in tissues could be directly correlated with its expression.

\section{Kv3.1 mRNA is expressed in both NM and NL}

We first used in situ hybridization to determine whether NM and NL neurons express Kv3.1 mRNA. The antisense Dig-labeled RNA probe was complementary to the last 363 bases of the $\mathrm{C}$ terminus of the rat Kv3.1b sequence (Luneau et al., 1991). In chickens, both NM and NL neurons expressed high levels of Kv3.1 mRNA (Fig. 3A,B). Kv3.1 mRNA was also abundantly expressed in owl NM and NL (Fig. 4A). Hybridization signal was detected in all neurons, with the intensity of signal appearing uniform along the entire extent of both nuclei. No signal was detected when sections were hybridized with sense probes (data not shown).

\section{Gradient of Kv3.1 immunoreactivity in the cochlear nucleus magnocellularis}

In the chicken $\mathrm{NM}$, the intensity of Kv3.1 immunoreactivity appeared relatively uniform throughout most of the nucleus (Fig. $3 C$ ). Individually stained neurons were readily discerned above a background of a lightly stained neuropil. The stained cell bodies were characterized by membrane-associated immunoreactivity, although staining of the cytosol was also apparent (Fig. 3E). Sometimes, stained processes were seen emanating from these neurons. Although there was not a prominent gradient of Kv3.1 immunoreactivity in chicken NM, cells in the caudalmost low BF region of NM displayed diminished levels of Kv3.1 immunoreactivity (Fig. 5B). Staining with a synaptic vesicle marker, SV2, delineated the full extent of chicken NM (Fig. $5 A$ ). A comparison of SV2 staining with Kv3.1 in this low BF region revealed extensive SV2-labeled neuropil and only lightly stained to unstained Kv3.1-positive neuropil and somata.

In the barn owl NM, Kv3.1 immunostaining diminished gradually along the tonotopic axis with greater intensity of label in high $\mathrm{BF}$ regions (Fig. $4 B, C$ ). Figure $4, D$ and $E$, compare levels of Kv3.1 staining in a high $\mathrm{BF}$ region and a low $\mathrm{BF}$ region of barn owl NM, respectively. Whereas the high BF region was characterized by intense staining of the somata, immunoreactivity of neurons in the low BF region was light. Kv3.1 immunostaining was largely confined to somata with little neuropil staining. At higher magnification, the Kv3.1 immunoproduct appeared most intense at the membrane, often seen surrounding a clear soma (Fig. $4 F$ ). Proximal processes were also labeled (Fig. 4D, arrows). We were unable to determine if these processes were axons or dendrites. Low levels of Kv3.1 immunoreactivity also characterized the low BF region of NM in the barn owl (Fig. 4E). This was not because of a decreased cell density in this region, because comparison of the staining patterns seen with SV2 and Kv3.1 antibodies (Fig. 5C,D) revealed that SV2-labeled terminals were extensive.

OD measurements were used to quantify the distribution of Kv3.1 immunoreactivity along the tonotopic gradient in both owl and chicken NM. The relative OD of individual stained neurons was measured at three levels, rostral (medial to NL), central (level of auditory nerve entry), and caudal (caudal to eighth nerve 

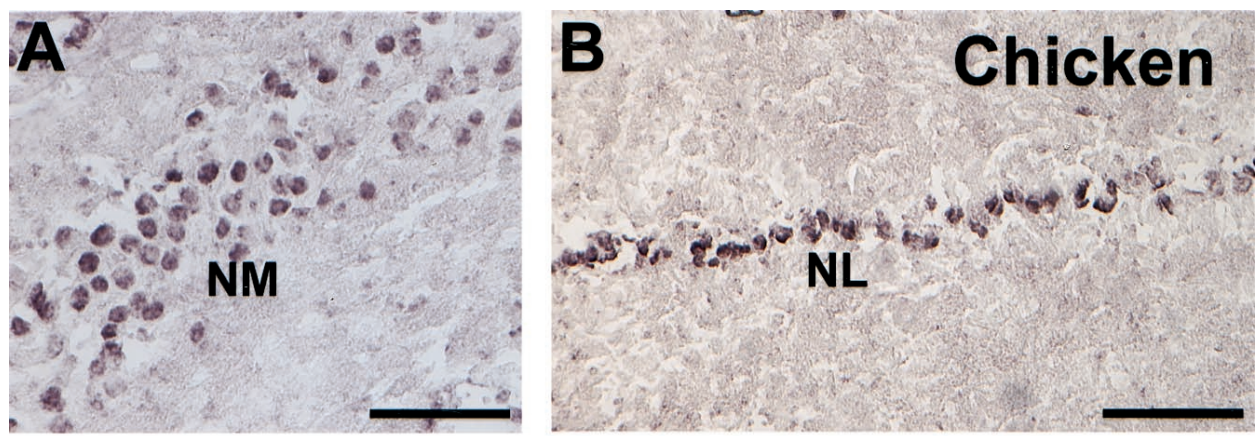

Figure 3. Kv3.1 expression in the brainstem auditory nuclei of the chicken. $A$, Dig-labeled Kv3.1 mRNA hybridization in NM. $B$, All NL neurons express the mRNA signal for $\mathrm{Kv} 3.1 . C, \mathrm{Kv} 3.1$ immunoreactivity in $\mathrm{NM}$ and $\mathrm{NL}$. The white box shows the region of NL magnified in $D$. $D$, Intensely immunoreactive neuropil in the high BF region of NL sandwiches a monolayer of apparently unstained cell bodies. E, Levels of Kv3.1 expression are relatively uniform in NM neurons. $F$, Neurons in the low $\mathrm{BF}$ region of NL are moderately immunopositive. Scale bars: $A, B, 100 \mu \mathrm{m} ; C$, $250 \mu \mathrm{m} ; D, 66 \mu \mathrm{m} ; E, 20 \mu \mathrm{m} ; F, 10 \mu \mathrm{m}$.
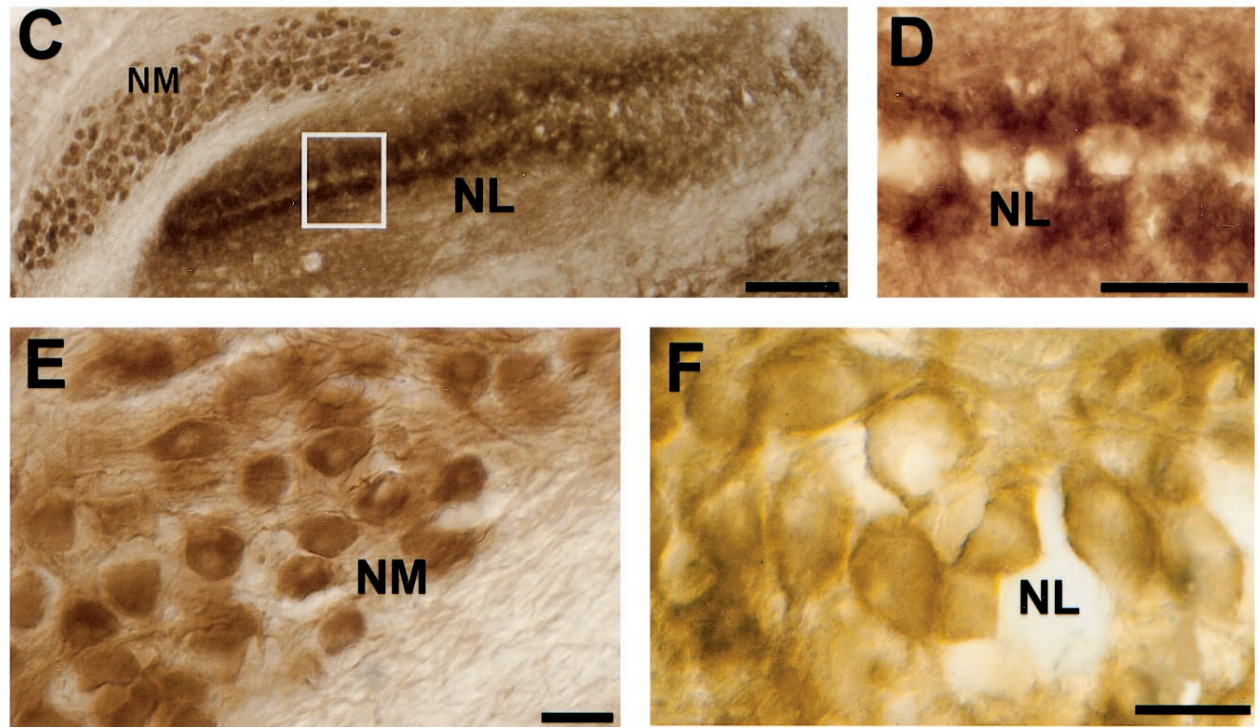

root). NM at each level was divided into three approximately equal regions to follow the tonotopic axis, mediodorsal, central, and lateroventral (Fig. 6, inserts). Because Kv3.1 immunostaining was largely confined to somata with very little neuropil staining, the relative OD was measured from individual neurons. In chicken, we found that relative OD values significantly decreased from rostral high $\mathrm{BF}$ regions to caudal low $\mathrm{BF}$ regions (Fig. 6A; Kruskal-Wallis test, $p<0.001)$. In the two more rostral sections, although there was a trend toward reduced OD levels in lower BF regions, pairwise comparisons between subdivisions did not reach significance. In the caudalmost section, significant differences in OD values between subdivisions was observed (MannWhitney $U$ test, $p<0.01)$. In the owl, the mean relative OD decreased systematically and significantly from mediodorsal to lateroventral regions in each section (Fig. 6B; Mann-Whitney $U$ test, $p<0.0001)$. The magnitude of change in OD levels across frequency was much greater in the barn owl than that seen in the chicken.

\section{Patterns of Kv3.1 immunoreactivity in NL differed between barn owl and chicken}

$\mathrm{NL}$ neurons in the chicken are bitufted with dorsal and ventral dendrites receiving inputs from the ipsilateral and contralateral inputs, respectively (Rubel and Parks, 1975; Jhaveri and Morest, 1982; Young and Rubel, 1983). By contrast, the barn owl NL dendrites are not polarized (except cells in the $1-2 \mathrm{kHz}$ regions of the nucleus), and NM inputs are perisomatic (Carr and Boudreau, 1993; Köppl and Carr, 1997).

In the chicken NL, the neuropil on either side of the monolayer of cell bodies was intensely immunoreactive (Fig. $3 C, D$, except low BF regions, see below). This neuropil includes the dorsal and ventral dendrites of NL neurons as well as the terminal arbors of $\mathrm{NM}$ axons. It was not clear if the cell bodies in this high BF region were immunonegative or if low levels of expression were masked by the intense immunoreactivity in the surrounding neuropil. In low BF regions, however, somata were clearly outlined by Kv3.1 immunolabel (Fig. 3F).

Kv3.1 immunoreactivity in owl NL was characterized by dense staining of the whole nucleus (Fig. $4 B$ ). Intensely immunolabeled somata were seen against a background of neuropil staining. At higher magnifications, the stained somata were characterized by a faint immunoreactive center surrounded by patchy perisomatic profiles (Fig. 4G). Under Nomarski optics these appeared to be stained puncta (Fig. 4H). The staining pattern was not uniform across the nucleus, but rather varied along the tonotopic axis. Labeling of both somata and neuropil was strongest in high BF regions and diminished in the very low BF lateral region of $\mathrm{NL}$ (Fig. 4B).

OD measurements were used to quantify the distribution of Kv3.1 immunoreactivity along the tonotopic gradient in both chicken and barn owl. Because there was prominent Kv3.1 immunoreactivity in both neuropil and cell bodies of NL, we did not measure the relative OD of individual neurons. In chicken, we measured OD of the dorsal neuropil to avoid the unstained cell body layer. In the barn owl, we measured the OD of regions that encompassed both neuropil and cell bodies. For both species, relative OD was measured along the tonotopic axis, from medial to lateral, within each transverse section. For chicken, no differences in OD were observed across the extent of the NL except for 


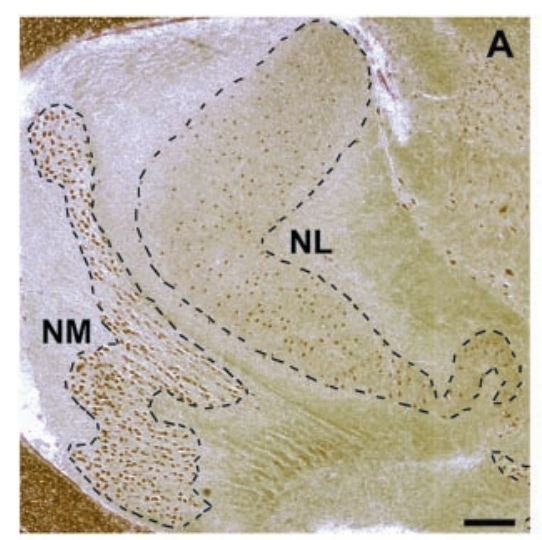

\section{Barn Owl}

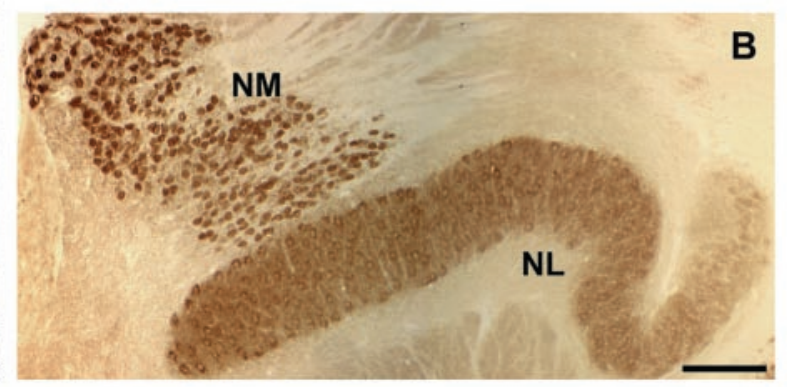

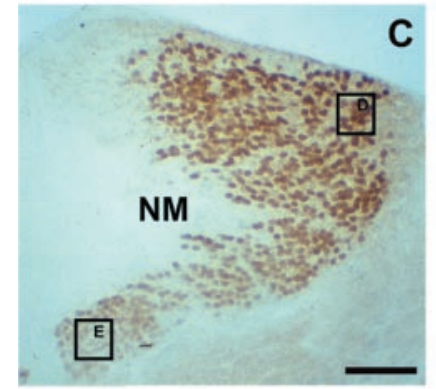
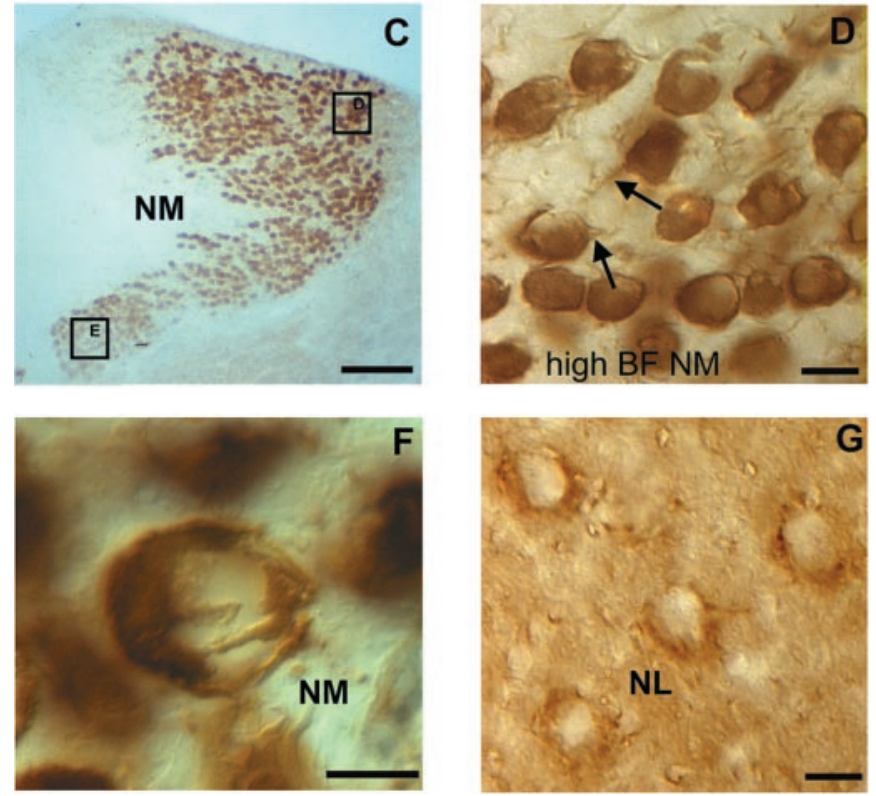

the very low $\mathrm{BF}$ regions where $\mathrm{OD}$ measures were significantly lower (Fig. $6 C$; Mann-Whitney $U$ test, $p<0.001$ ). In the barn owl, relative OD was high across the entire rostral $\mathrm{NL}$, although the most medial (high $\mathrm{BF}$ ) portion showed a significant increase in OD over the other more lateral regions (Fig. 6D). For caudal regions of the owl NL (low $\mathrm{BF}$ ), there was a significant decrease in relative OD along the tonotopic axis (Fig. 6D; Mann-Whitney $U$ test, $p<0.0001)$.

\section{NM cell bodies but not endbulbs are Kv3.1-immunopositive}

Because it was difficult to determine whether Kv3.1 staining was presynaptic and/or postsynaptic, we used ultrastructural techniques to define the subcellular localization of the Kv3.1 protein. In the chicken, Kv3.1 immunoproduct was found in NM somata but not their endbulb inputs (Fig. $7 A$ ). Somatic label was concentrated beneath the membrane (arrow) and also found distributed in the cytoplasm, mostly associated with the endoplasmic reticulum. Membrane labeling was heterogeneous, but without threedimensional reconstruction and postembedding EM, it is not possible to determine whether the observed patches of Kv3.1immunoreactive material were associated with any particular postsynaptic specialization. Similarly, Kv3.1 immunoproduct was confined to NM somata in the barn owl. Figure $7 B$ shows a stained somatic spine (long arrow) indenting an unstained end-
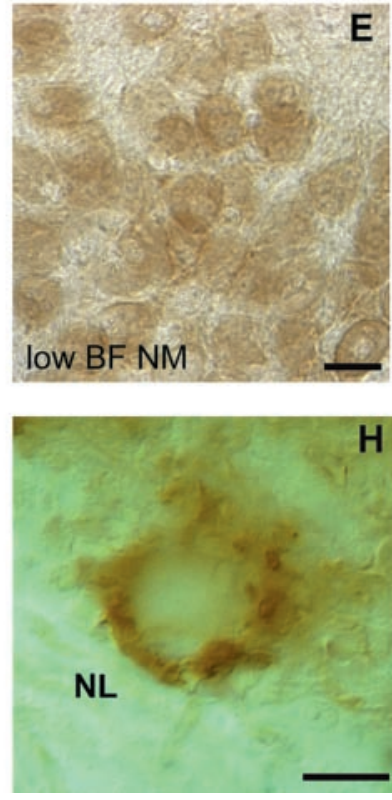
dendrites or axons. Neuropil labeling is faint. E, Extremely low levels of Kv3.1 protein in cells encoding low BF. $F$, A single NM neuron viewed under Nomarski optics. The region of the endbulb is intensely immunopositive. $G$, Perisomatic label in NL neurons with moderately labeled surrounding neuropil. $H$, Single NL neuron viewed under Nomarski optics. The cell is surrounded by immunoreactive puncta. Scale bars: $A, 1$ $\mathrm{mm} ; B, 0.5 \mathrm{~mm} ; \mathrm{C}, 250 \mu \mathrm{m} ; D, E, G, 20$ $\mu \mathrm{m} ; F, H, 10 \mu \mathrm{m}$.

Figure 4. Kv3.1 in the auditory brainstem nuclei of the owl. A, In situ hybridthe NM and NL of the owl. $B$, Expression of Kv3.1 protein in NM and NL. Both nuclei display a gradient in levels of Kv3.1 immunoreactivity. $C$, Gradient of Kv3.1 expression along the tonotopic axis in NM. High BF neurons are intensely labeled, whereas low BF neurons are fainter. $D$, High BF NM neurons, arrows bulb. Like in the chicken NM, extrasynaptic staining was also seen beneath the membrane (Fig. 7B, short arrow).

\section{Kv3.1 is differentially distributed in NL of owl and chicken}

In the chicken NL, Kv3.1 immunoproduct was typically found outlining the somata (Fig. $8 A$ ) and proximal dendrites, even in high $\mathrm{BF}$ regions, where labeled cell bodies could not be seen at the level of the light microscope (Fig. 2D). Surprisingly, we did not find evidence for localization of Kv3.1 product in the presynaptic terminals on chicken NL neurons. In the barn owl, however, the majority of Kv3.1 immunoproduct was concentrated in the NM axons within NL. Label was seen under the myelin, but was most heavy at the nodes and preterminal segments (Fig. 8C). Owl NL somata were also labeled, although this label was not as intense as that of the NM preterminal axons and did not appear to extend out to include the distal dendrites (Fig. 8B).

\section{DISCUSSION}

Kv3.1 channels are delayed rectifiers that open after depolarization to potentials more than $-10 \mathrm{mV}$ and deactivate rapidly after repolarization (Grissmer et al., 1994; Vega-Saenz de Miera et al., 1994; Kanemasa et al., 1995; Hernández-Pineda et al., 1999). Computer simulations and physiological studies suggest that Kv3.1 expression reduces the width of the AP and allows cells to 

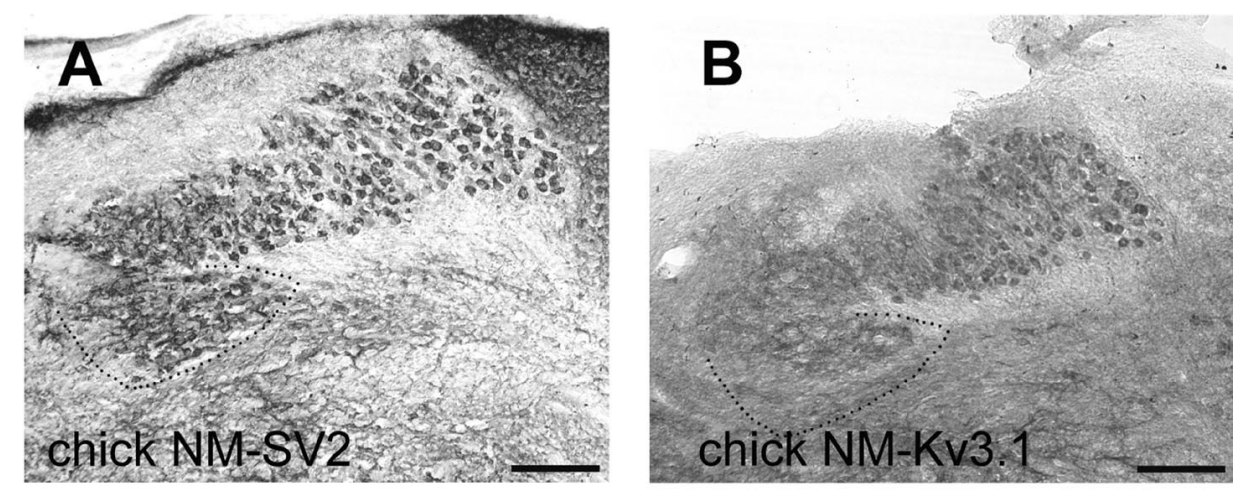

Figure 5. Kv3.1 in the low BF region of NM in the chicken and owl. Cells in the caudalmost region of NM are delineated by staining with the synaptic vesicle marker (SV2). $A$, Chicken; $C$, owl. Levels of Kv3.1 immunoreactivity are very low in the same region. $B$, Chicken, $D$, owl. Scale bars, $100 \mu \mathrm{m}$.
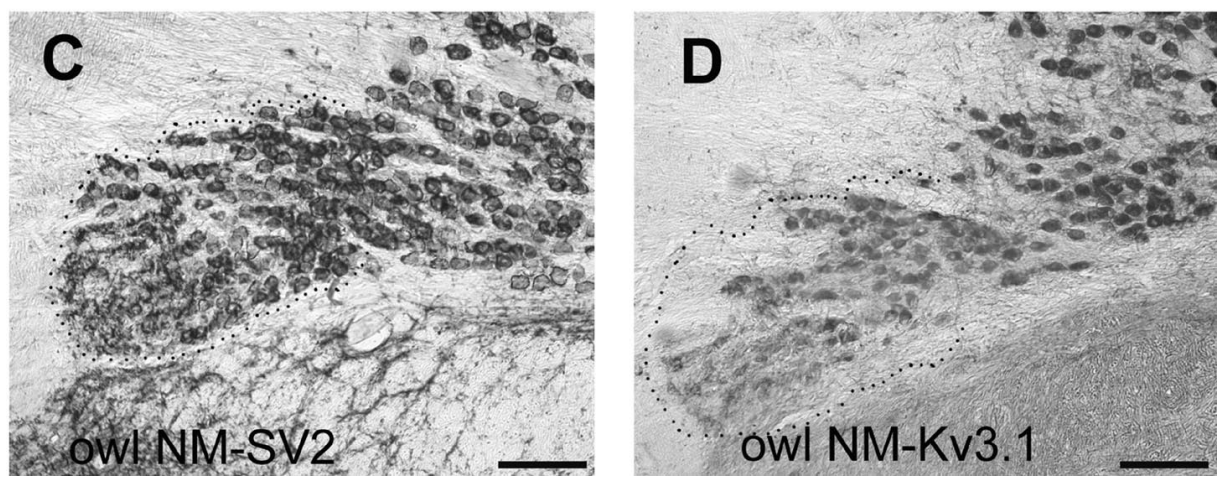

respond to high rates of stimulation (Perney and Kaczmarek, 1997; Erisir et al., 1999). We propose that differences in Kv3.1 expression between barn owls and chickens reflect specializations for phase-locking to high frequencies in the barn owl.

There were two major differences in the pattern of Kv3.1 expression between the chicken and the barn owl. First, in the owl, a prominent gradient of Kv3.1 staining was observed in NM and NL, with highest levels in rostral high $\mathrm{BF}$ regions and low to negligible levels in caudal low BF regions. In contrast, the chicken NM displayed only a mild gradient in Kv3.1 protein levels, whereas levels of Kv3.1 in chicken NL were uniformly high except in the low BF region. Tonotopic gradients may be more obvious in the barn owl because its frequency range has been extended by about an octave as compared to the chicken (Konishi, 1973; Gray and Rubel, 1985). We did not observe noticeable differences in Kv3.1 mRNA levels across the tonotopic axis in either chickens or barn owls, despite the clear gradient in Kv3.1 protein expression. Because we did not use quantitative methods to assess Kv3.1 mRNA levels, however, differences in expression may not have been detectable. The lack of a mRNA gradient might also have been attributable to differences in mRNA transport, stability, or translational regulation across the tonotopic map.

The second major difference in the expression pattern of Kv3.1 between the chicken and the owl was the presence of Kv3.1 in the presynaptic elements in the owl NL. In the chicken NL, NM preterminal segments showed minimal staining, whereas the NL neurons were immunoreactive. This pattern of expression was reversed in the owl in which the NM axons and preterminal segments were intensely immunoreactive, and the NL neurons had lower levels of immunoproduct. Although the NL neurons of the owl expressed Kv3.1 mRNA, the immunoreactivity in NL appeared to be largely derived from perisomatic Kv3.1-positive NM elements, raising the possibility that the protein may be differentially targeted depending on the neuronal population (Weiser et al., 1995). The observed gradient in Kv3.1 expression in owl NL presumably derives from a gradient in expression in $\mathrm{NM}$ axons and their preterminal segments.

\section{Physiology and modeling suggest that Kv3.1 shortens AP duration and mediates high rates of activity}

Principal cells in the avian NM and the mammalian medial nucleus of the trapezoid body (MNTB) exhibit a similar repertoire of outward currents. These mainly consist of low-threshold currents (LTCs) and high-threshold currents (HTCs) (Reyes et al., 1994; Brew and Forsythe, 1995; Wang et al., 1998a; Rathouz and Trussell, 1998). The HTC activates relatively quickly $(\tau<5$ $\mathrm{msec}$ ) and also deactivates rapidly. In chicken NM neurons the HTC is the dominant outward current at positive voltages, comprising $80 \%$ of the total current (Rathouz and Trussell, 1998). The predominance of the HTC at positive potentials suggests that it would play a key role in repolarization of APs. Indeed, application of blockers of the HTC resulted in spike broadening and reduction of the afterhyperpolarization in NM and MNTB (Reyes et al., 1994; Rathouz and Trussell, 1998; Wang et al., 1998a).

The defining features of the HTC closely resemble the Kv3.1 conductance in heterologous expression systems (Grissmer et al., 1994; Vega-Saenz de Miera et al., 1994; Kanemasa et al., 1995; Hernández-Pineda et al., 1999). Nevertheless, because functional potassium channels are often heterotetramers composed of similar subfamily members (Christie et al., 1990; Isacoff et al., 1990; Ruppersberg et al., 1990; Weiser et al., 1994), we cannot rule out the possibility that Kv3.1 heteromers, rather than Kv3.1 homomers, underlie the HTC in auditory neurons. Indeed, Kv3.1 is often seen coexpressed with other Kv3 subfamily members in mammalian neurons (W. Li, L. K. Kaczmarek, and T. M. Perney, unpublished observations) (Hernández-Pineda et al., 1999; Grigg et al., 2000). The expression patterns of other Kv3 subfamily members are unknown in avians. 

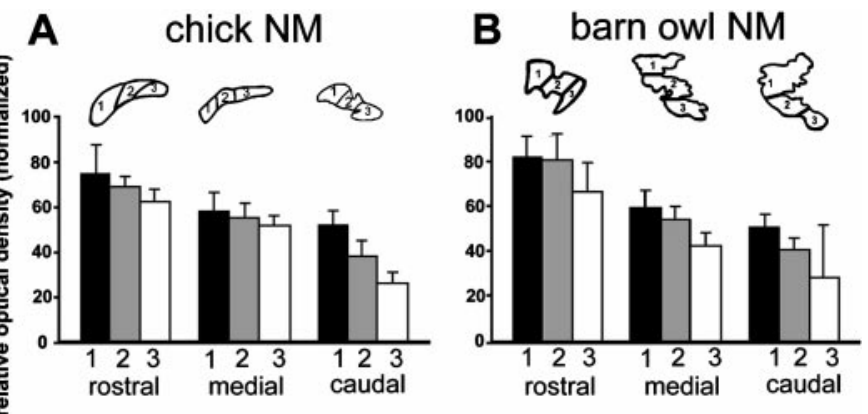

location in NM
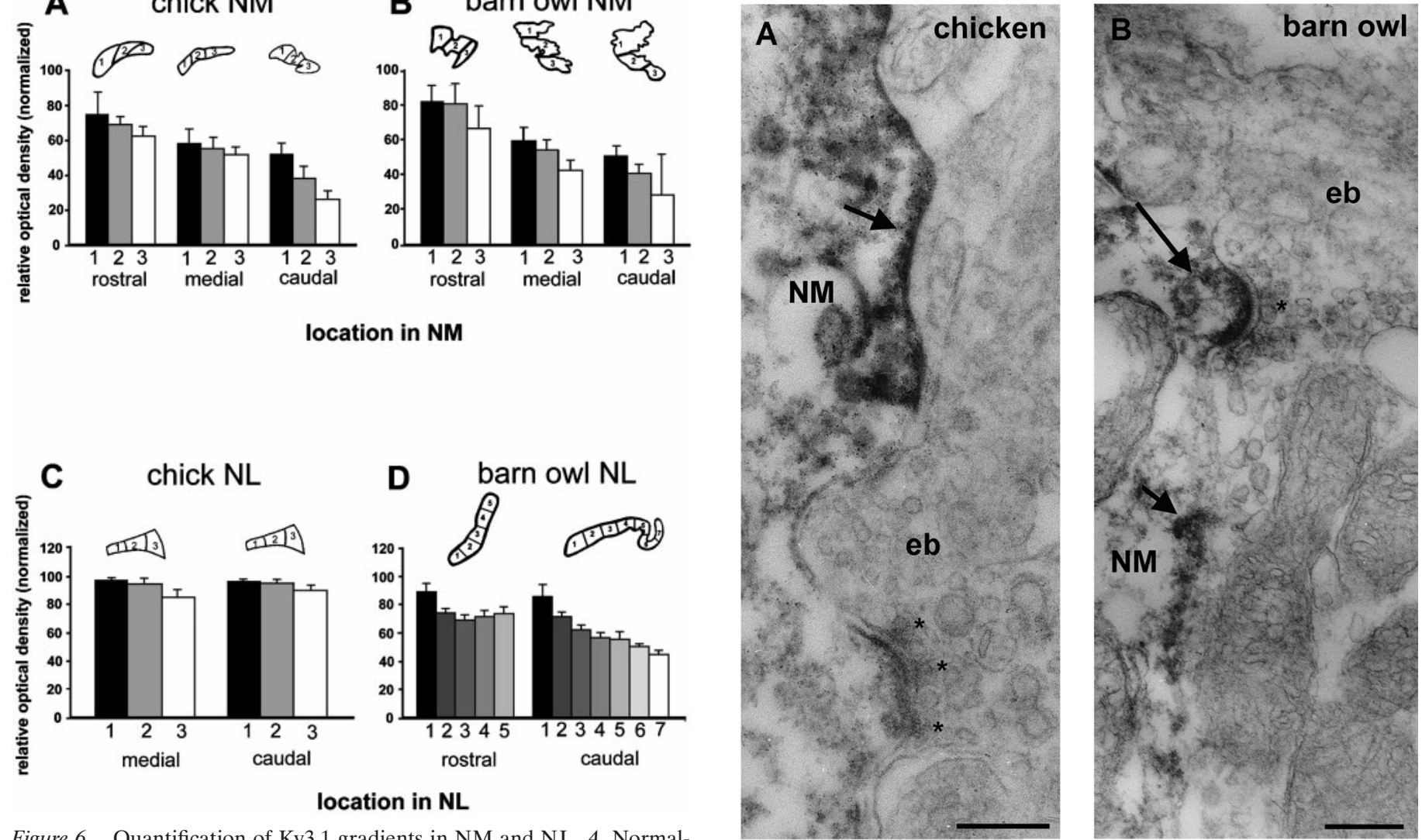

Figure 6. Quantification of Kv3.1 gradients in NM and NL. A, Normalized relative OD values measured from rostral, central, and caudal regions of chick NM. Inserts show the outline of each NM section with the mediodorsal, central, and ventrolateral subdivisions from which measurements were made. Kruskal-Wallis tests on each region did not show a significant difference in OD between subdivisions in both the rostral and central regions, but the OD values from subdivisions in the caudal region were significantly different. Pairwise analyses showed that $O D$ values were significant when mean OD of a subdivision in one region was individually compared with the mean OD of subdivisions at the other locations (Mann-Whitney $U$ test, $p<0.0001$ ). OD measurements were made from 15 cells within each subdivision. $B$, Normalized relative OD values measured from rostral, central, and caudal regions of owl NM. Inserts show the outline of each NM section with the mediodorsal, central, and ventrolateral subdivisions from which measurements were made. Kruskal-Wallis tests on each section showed a significant difference in OD between subdivisions. Pairwise analysis showed that OD value of each subdivision was significantly different (Mann-Whitney $U$ test, $p<$ $0.0001)$. Numbers of cells within each subdivision are as follows: rostral 1 , $n=22$; rostral $2, n=33$; rostral $3, n=25$; medial $1, n=56$; medial $2, n=$ 46; medial 3, $n=41$; caudal $1, n=61$; caudal $2, n=76$; caudal $3, n=90$. $C$, Normalized relative OD values measured from medial (left $t$ and caudal (right) regions of chick NL. Inserts show the outline of each NL section divided into three subdivisions from which measurements were made. The tonotopic axis proceeds from high (1) to low (3) in all sections. Optical density measurements were made along the proximal region of the dorsal dendritic tufts. Kruskal-Wallis tests on each section showed a significant difference in OD within each section. Pairwise analysis of OD values for the caudal NL sections showed that OD values from each subdivision were significantly different only between medial 1 and 3 , medial 2 and 3, caudal 1 and 3, and caudal 2 and 3 (Mann-Whitney $U$ test, $p<0.0001)$. Fifteen regions within each subdivision were sampled $(n=$ 15). $D$, Normalized relative OD values measured from rostral (left $t$ and caudal (right) regions of barn owl NL. Inserts show the outline of each NL section divided into 0.5 - $\mathrm{mm}$-long subdivisions from which measurements were made. The tonotopic axis proceeds from high (1) to low (5) in each section. Kruskal-Wallis tests on each section showed a significant difference in OD between subdivisions. Pairwise analysis of OD values for the caudal NL sections showed that OD values from each subdivision were significantly different, except between subdivisions 4 and 5 (Mann-Whitney $U$ test, $p<0.0001$ ). Pairwise analysis of OD values for the rostral NL sections showed that OD values from each subdivision were not significantly different, except for subdivisions 1 which was different from divisions 2, 3, 4, and 5 (Mann-Whitney $U$ test, $p<0.0001$ ).

Figure 7. EM immunolocalization of Kv3.1b in NM. A, Unlabeled auditory nerve terminal $(e b)$ forms a synapse on a labeled chicken NM neuron (cf. Parks, 1981). In this section, three presynaptic dense projections may be seen at the active zone (*) of a synapse on a cytoplasmic spine that indents into the endbulb. The postsynaptic density is thick and can be differentiated from the dense Kv3.1 immunoreactivity distributed under the membrane of the NM cell body (arrow). The presynaptic membrane also contains membranous cisterns and coated vesicles. $B$, Unlabeled auditory nerve terminal $(e b)$ synapses on a labeled owl cell body $(N M)$. The large arrow marks immunoreactivity associated with a postsynaptic density opposed to a synapse (*), and a short arrow marks Kv3.1 label distributed under the cell body membrane. Scale bar, $0.25 \mu \mathrm{m}$ (applies to both $A$ and $B$ ).

\section{Significance of Kv3.1 in the auditory system}

Localization of sounds is made possible by the fact that neurons in NL are sensitive to the phase difference of sound waves at each ear (for review, see Joris et al., 1998). Phase information is encoded by action potentials that occur at a particular phase of the stimulus cycle with minimal jitter (phase-locking; Sullivan and Konishi, 1984; Carr and Konishi, 1990; Warchol and Dallos, 1990; Köppl, 1997). The ability of the auditory system to use ITD cues to localize sounds requires adaptations that enhance the ability of auditory neurons to preserve temporal information at frequencies up to $10 \mathrm{kHz}$ in the barn owl (Sullivan and Konishi, 1984; Köppl, 1997).

Temporal coding in auditory neurons is associated with a number of specializations, including endbulb synapses, AMPA receptors and the LTC (see introductory remarks) (for review, see Oertel, 1999; Trussell, 1999). The increased levels of HTC associated with Kv3.1 expression could also contribute to precise temporal coding by restricting the width of the AP invading the NM terminals in NL. NM neurons are also notable for brief spikes (Carr and Konishi, 1990; Reyes et al., 1994), and a small 

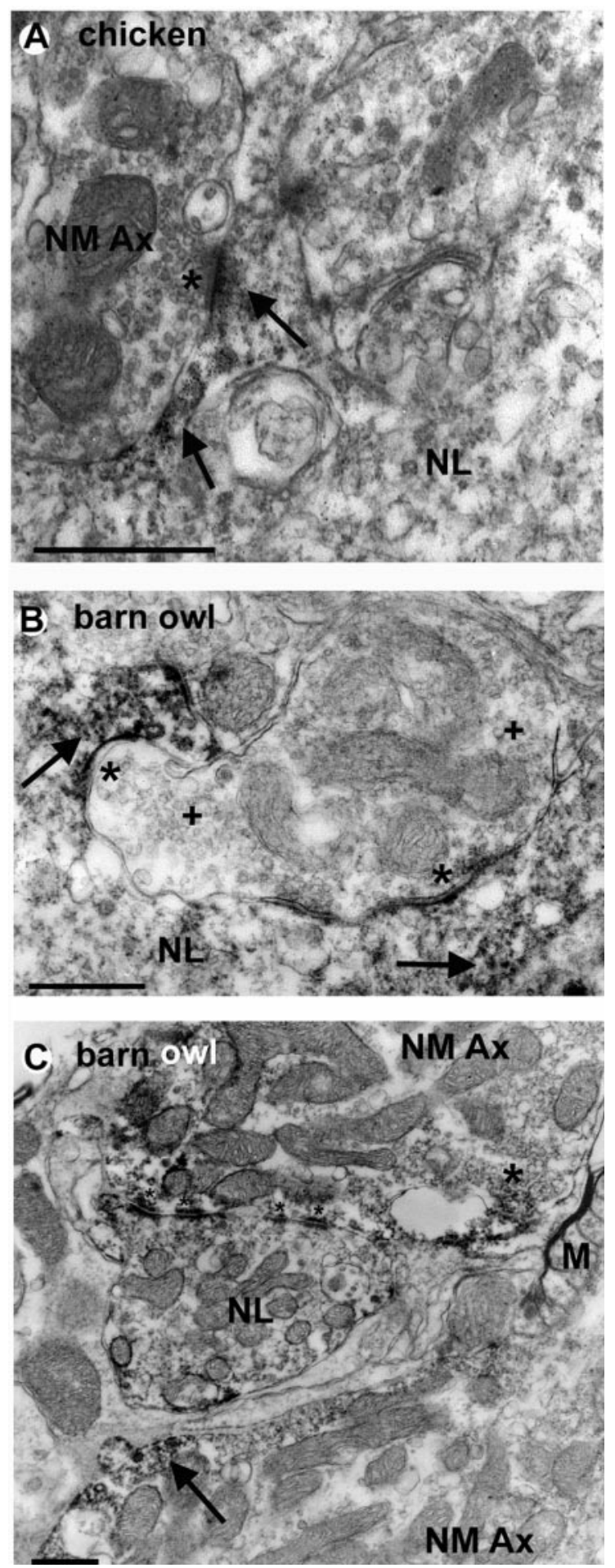

Figure 8. EM immunolocalization of Kv3.1b in NL. A, Labeled chicken NL neuron showing a portion of a proximal dendrite. Synapse $(*)$ between a presumed NM terminal $(A x)$ and the NL dendrite. Patches of postsynaptic label marked with arrows (for a detailed description of this synapse type, see Parks et al., 1983). B, Non-NM terminal with pleomorphic vesicles $(+)$ and with small presynaptic densities makes a symmetric synapse $(*)$ on labeled (arrows) NL neuron (for a detailed description of this synapse type, see Carr and Boudreau, 1993). C, Two labeled preterminal elements $(N M A x)$ and a postsynaptic profile $(N L)$ in owl NL. At bottom right, one NM axon loses its myelin $(M)$ and exhibits a patchy deposition of Kv3.1-immunoreactive product (arrow) under the preterminal membrane. Another NM terminal (top, NM $A x$ ) forms a synapse (*) on a labeled NL profile. Attachment plaques also link this NM terminal to the postsynaptic profile (small *). Scale bar: $A, 0.25 \mu \mathrm{m} ; B, C, 0.5 \mu \mathrm{m}$. modification in the shape of the presynaptic spike could dramatically change the amount of calcium entering the neuron and subsequent transmitter release (for review, see Kaczmarek and Levitan, 1987; Sabatini and Regehr, 1999). Modeling of coincidence detector neurons suggest that an increase in the width of the input EPSC could impair ITD coding (Simon et al., 1999). Thus, the selective increase of Kv3.1-like currents in the NM delay line axons may contribute to the temporal synchrony necessary for accurate phase locking.

The time coding neurons of NM and NL are not only accurate, but they also fire at very high rates in both chicken and barn owl (Sullivan and Konishi, 1984; Carr and Konishi, 1990; Warchol and Dallos, 1990). NM has both a high spontaneous rate (Köppl, 1997) and a high driven rate (Sullivan and Konishi, 1984; Warchol and Dallos, 1990), whereas NL neurons have high driven rates (Carr and Konishi, 1990). No differences, however, in either spontaneous or driven rates has been observed across the tonotopic axis. Thus, whereas expression of Kv3.1 might allow NM and NL neurons fire at high rates, the observed gradient also suggests that Kv3.1 expression enhances temporal precision.

Gradients in expression level of gene products are not uncommon in the auditory system. Frequency selectivity in nonmammalian hair cells is enhanced by the systematic variation in hair cell membrane properties along the tonotopic axis (for review, see Fettiplace and Fuchs, 1999). This difference is most likely attributable to the differential expression of the splice variants for $\mathrm{Ca}^{2+}$-activated $\mathrm{K}^{+}$channels (Bk channels) and their $\beta$ subunits (Navaratnam et al., 1997; Ramanathan et al., 1999, 2000). A differential distribution of $\mathrm{Kv} 3.1$ and $\mathrm{Bk}$ channels was also observed across the tonotopic gradient in the spiral ganglion of mouse (Adamson et al., 1999). In the inferior colliculus of mammals, gradients of expression of $\mathrm{GABA}_{\mathrm{A}}$ receptors, GABA, glycine receptors, and perhaps Kv1.1 (Glendenning and Baker, 1988; Edgar and Schwartz, 1990; Fubara et al., 1996; Grigg et al., 2000) have been observed.

\section{Comparisons with Kv3.1 expression in mammals}

The mammalian auditory system has two populations of neurons, bushy cells in the cochlear nucleus $(\mathrm{CN})$ and neurons of the medial nucleus of the trapezoid body (MNTB), which receive secure endbulb synapses and are specialized for preserving temporal information. Like NM neurons, both these neuronal cell types express high levels of Kv3.1 mRNA (Perney et al., 1992; Weiser et al., 1994; Grigg et al., 2000). Prominent membraneassociated Kv3.1 immunoreactivity was also observed in the somata and proximal dendrites of these neurons (Perney and Kaczmarek, 1997) (Li, Kaczmarek, and Perney, unpublished observations). In addition, Kv3.1 immunoreactivity also appears to be present at or near axonal terminals of bushy cells and MNTB neurons in the lateral superior olive (Wang et al., 1998b, their Fig. 1C; Perney et al., 1993).

In mammals, the neurons of the medial superior olivary nucleus (MSO) act as coincidence detectors to encode ITD (Yin and Chan 1990; Joris et al., 1998). Remarkably, MSO neurons do not express either Kv3.1 mRNA or Kv3.1 protein (Grigg et al., 2000) (Li, Kaczmarek, and Perney, unpublished observations). Although MSO neurons do not express Kv3.1, they do express high levels of Kv3.3 message (Grigg et al., 2000) (Li, Kaczmarek, and Perney, unpublished observations). Thus, differences in Kv3.1 expression between NL and MSO structures may reflect species differences in the expression of Kv3 subfamily members. 


\section{REFERENCES}

Adamson CL, Perney TM, Peng L, Davis RL (1999) Immunohistochemical distribution of potassium channel subunits in murine spiral ganglion neurons. Soc Neurosci Abstr 25:1669.

Brew HM, Forsythe ID (1995) Two voltage-dependent K+ conductances with complementary functions in postsynaptic integration at a central auditory synapse. J Neurosci 15:8011-8022.

Buckley K, Kelly RB (1985) Identification of a transmembrane glycoprotein specific for secretory vesicles of neural and endocrine cells. J Cell Biol 100:1284-1294.

Carr CE, Boudreau RE (1991) Central projections of auditory nerve fibers in the barn owl. J Comp Neurol 314:306-318.

Carr CE, Boudreau RE (1993) Organization of the nucleus magnocellularis and the nucleus laminaris in the barn owl: encoding and measuring interaural time differences. J Comp Neurol 334:337-355.

Carr CE, Konishi M (1990) A circuit for detection of interaural time differences in the brainstem of the barn owl. J Neurosci 10:3227-3246.

Christie MJ, North RA, Osborne PB, Douglass J, Adelman JP (1990) Heteropolymeric potassium channel expressed in Xenopus oocytes from cloned subunits. Neuron 4:405-411.

Edgar PP, Schwartz RD (1990) Localization and characterization of 35S-t butylbicyclophosphorothionate binding in rat brain: an autoradiographic study. J Neurosci 10:603-612.

Erisir A, Lau D, Rudy B, Leonard CS (1999) The function of specific $\mathrm{K}+$ channels in sustained high frequency firing of fast spiking interneurons. J Neurophysiol 82:2476-2489.

Fettiplace R, Fuchs PA (1999) Mechanisms of hair cell tuning. Annu Rev Physiol 61:809-34.

Fubara BM, Casseday JH, Covey E, Schwartz-Bloom RD (1996) Distribution of $\mathrm{GABA}_{\mathrm{A}}, \mathrm{GABA}_{\mathrm{B}}$, and glycine receptors in the central auditory system of the big brown bat, Eptesicus fuscus. J Comp Neurol 369:83-92.

Glendenning KK, Baker BN (1988) Neuroanatomical distribution of receptors for three potential inhibitory neurotransmitters in the brainstem auditory nuclei of the cat. J Comp Neurol 275:288-308.

Gray L, Rubel EW (1985) The development of absolute thresholds in chickens. J Acoust Soc Amer 77:1162-1172.

Grigg JJ, Brew HM, Tempel BL (2000) Differential expression of voltage-gated potassium channel genes in auditory nuclei of the mouse brainstem. Hear Res 140:77-90.

Grissmer S, Nguyen AN, Aiyar J, Hanson DC, Mather RJ, Gutman GA, Karmilowicz MJ, Auperin DD, Chandy KG (1994) Pharmacological characterization of five cloned voltage-gated $\mathrm{K}+$ channels, types Kv1.1, $1.2,1.3,1.5$, and 3.1 , stably expressed in mammalian cell lines. Mol Pharmacol 45:1227-1234.

Hernández-Pineda R, Chow A, Amarillo Y, Moreno H, Saganich M, Vega-Saenz de Miera E, Hernández-Cruz A, Rudy B (1999) Kv3.1Kv3.2 heteromultimeric channels underlie a high voltage-activating component of the delayed rectifier $\mathrm{K}+$ current in projecting neurons from the globus pallidus. J Neurophysiol 82:1512-1528.

Isacoff EY, Jan YN, Jan LY (1990) Evidence for the formation of heteromultimeric potassium channels in Xenopus oocytes. Nature 345:530-534.

Jeffress LA (1948) A Place theory of sound localization. J Comp Physiol Psychol 41:35-39.

Jhaveri S, Morest DK (1982) Sequential alterations of neuronal architecture in nucleus magnocellularis of the developing chicken: a Golgi study. Neurosci 7:837-853.

Joris PX, Smith PH, Yin TCT (1998) Coincidence detection in the auditory system: 50 years after Jeffress. Neuron 21:1235-1238.

Kaczmarek LK, Levitan IB (1987) Neuromodulation: the biochemical control of neuronal Excitability. New York: Oxford UP.

Kanemasa T, Gan L, Perney TM, Wang LY, Kaczmarek LK (1995) Electrophysiological and pharmacological characterization of a mammalian Shaw channel expressed in NIH 3T3 fibroblasts. J Neurophysiol 74:207-217.

Klump GM (2000) Sound localization in birds. In: Comparative hearing: birds and reptiles. Handbook of Auditory Research. New York: Springer.

Konishi M (1973) How the owl tracks its prey. Am Sci 61:414-424.

Köppl C (1997) Phase locking to high frequencies in the auditory nerve and cochlear nucleus magnocellularis of the barn owl Tyto alba. J Neurosci 9:3312-3321.

Köppl C, Carr CE (1997) Low-frequency pathway in the barn owl's auditory brainstem. J Comp Neurol 2:265-82.

Levin MD, Kubke MF, Schneider M, Wenthold R, Carr CE (1997) Localization of AMPA-selective glutamate receptors in the auditory brainstem of the barn owl. J Comp Neurol 378:239-253.

Luneau CJ, Williams JB, Marshall J, Levitan ES, Oliva C, Smith JS, Antanavage J, Folander K, Stein RB, Swanson R, Kaczmarek LK, Burhow SA (1991) Alternative splicing contributes to K+ channel diversity in the mammalian central nervous system. Proc Natl Acad Sci USA 88:3932-3936.
Manis PB, Marx SO (1991) Outward currents in isolated ventral cochlear nucleus neurons. J Neurosci 11:2865-2880.

Martina M, Schultz JH, Ehmke H, Monyer H, Jonas P (1998) Functional and molecular differences between voltage-gated $\mathrm{K}+$ channels of fastspiking interneurons and pyramidal neurons of rat hippocampus. J Neurosci 18:8111-8125.

Massengill JL, Smith MA, Son DI, O’Dowd DK (1997) Differential expression of K4-AP currents and Kv3.1 potassium channel transcripts in cortical neurons that develop distinct firing phenotypes. J Neurosci 17:3136-3147.

Navaratnam DS, Bell TJ, Tu TD, Cohen EL, Oberholtzer JC (1997) Differential distribution of $\mathrm{Ca} 2+$ activated $\mathrm{K}+$ channel splice variants among hair cells along the tonotopic axis of the chick cochlea. Neuron 19:1077-1085.

Oertel D (1983) Synaptic responses and electrical properties of cells in brain slices of the mouse anteroventral cochlear nucleus. J Neurosci 3:2043-2053

Oertel D (1999) The role of timing in the brain stem auditory nuclei of vertebrates. Annu Rev Physiol 61:497-519.

Overholt EM, Rubel EW, Hyson RL (1992) A circuit for coding interaural time differences in the chick brain stem. J Neurosci 12:1698-1708.

Parks TN (1981) Morphology of axosomatic endings in an avian cochlear nucleus: nucleus magnocellularis of the chicken. J Comp Neurol 203:425-440.

Parks TN, Rubel EW (1975) Organization and development of the brain stem auditory nuclei of the chicken: organization of projections from nucleus magnocellularis to nucleus laminaris. J Comp Neurol 164:435-448.

Parks TN, Collins P, Conlee JW (1983) Morphology and origin of axonal endings in nucleus laminaris of the chicken. J Comp Neurol 214:32-42

Perney TM, Kaczmarek LK (1997) Localization of a high threshold potassium channel in the rat cochlear nucleus. J Comp Neurol 386:178-202.

Perney TM, Marshall J, Martin KA, Hockfield S, Kaczmarek LK (1992) Expression of the mRNAs for the Kv3.1 potassium channel gene in the adult and developing rat brain. J Neurophysiol 68:756-766.

Perney TM, Meloni E, Eager P, Kaczmarek LK, Schwartz IR (1993) Subcellular localization of the Kv3.1 potassium channel protein in the rat auditory brainstem. Soc Neurosci Abstr 17:1204.

Raman IM, Trussell LO (1992) The kinetics of the response to glutamate and kainate in neurons of the avian cochlear nucleus. Neuron 9:173-186.

Raman IM, Zhang S, Trussell LO (1994) Pathway-specific variants of AMPA receptors and their contribution to neuronal signaling. J Neurosci 4:4998-5010.

Ramanathan K, Michael TH, Jiang GJ, Hiel H, Fuchs PA (1999) A molecular mechanism for electrical tuning of cochlear hair cells. Science 283:215-217.

Ramanathan K, Michael TH, Fuchs PA (2000) Beta subunits modulate alternatively spliced, large conductance, calcium-activated potassium channels of avian hair. J Neurosci 20:1675-1684.

Rathouz M, Trussell L (1998) A characterization of outward currents in neurons of the nucleus magnocellularis. J Neurophysiol 80:2824-2835.

Ravindranathan A, Parks TN, Rao MS (1996) Flip and flop isoforms of chick brain AMPA receptor subunits: cloning and analysis of expression patterns. NeuroReport 7:2707-2711.

Ravindranathan A, Parks TN, Rao MS (1997) New isoforms of the chick glutamate receptor subunit GluR4: molecular cloning, regional expression and developmental analysis. Brain Res Mol Brain Res 50:143-153.

Reyes AD, Rubel EW, Spain WJ (1994) Membrane properties underlying the firing of neurons in the avian cochlear nucleus. $J$ Neurosci 14:5352-5364.

Rose JE, Brugge JF, Anderson DJ, Hind JE (1967) Phase-locked response to low-frequency tones in single auditory nerve fibers of the squirrel monkey. J Neurophysiol 30:769-793.

Rubel EW, Parks TN (1975) Organization and development of brain stem auditory nuclei of the chicken: tonotopic organization of n. magnocellularis and n. laminaris. J Comp Neurol 164:411-434.

Rubel EW, Parks TN (1988) Organization and development of the avian brainstem auditory system. In: Auditory function (Edelman GM, Gall WE, Cowan WM, eds), pp 3-92. New York: Wiley.

Rudy B, Chow A, Lau D, Amarillo Y, Ozaita A, Saganich M, Moreno H, Nadal MS, Hernandez Pineda R, Hernandez-Cruz A, Erisir A, Leonard C, Vega-Saenz de Miera E (1999) Contributions of Kv3 channels to neuronal excitability. Ann NY Acad Sci 868:304-343.

Ruppersberg JP, Schroter KH, Sakmann B, Stocker M, Sewing S, Pongs O (1990) Heteromultimeric channels formed by rat brain potassium channel. Nature 345:535-537.

Sabatini BL, Regehr WG (1999) Timing of synaptic transmission. Annu Rev Physiol 61:521-542.

Simon JZ, Carr CE, Shamma SA (1999) A dendritic model of coincidence detection in the avian brainstem. Neurocomp 27:263-269.

Sullivan WE, Konishi M (1984) Segregation of stimulus phase and in- 
tensity coding in the cochlear nucleus of the barn owl. J Neurosci 4:1787-1799.

Takahashi T, Konishi M (1988) Projections of nucleus angularis and nucleus laminaris to the lateral lemnisical nuclear complex of the barn owl. J Comp Neurol 274:212-238.

Trussell LO (1999) Synaptic mechanisms for coding timing in auditory neurons. Annu Rev Physiol 61:477-496.

Vega-Saenz de Miera E, Weiser M, Kentros C, Lau D, Moreno H, Serodio P, Rudy B (1994) Shaw-related K+ channels in mammals. In: Handbook of membrane channels (Peracchia C, ed), pp 41-78. Orlando, FL: Academic.

Wang LY, Gan L, Forsythe ID, Kaczmarek LK (1998a) Contribution of the Kv3.1 potassium channel to high-frequency firing in mouse auditory neurones. J Physiol (Lond) 509:183-194.

Wang LY, Gan L, Perney TM, Schwartz I, Kaczmarek LK (1998b) Activation of Kv3.1 channels in neuronal spine-like structures may induce local potassium ion depletion. Proc Natl Acad Sci USA 95:1882-1887.

Warchol ME, Dallos P (1990) Neural coding in the chick cochlear nucleus. J Comp Physiol 166:721-734.

Weiser M, Vega-Saenz de Miera E, Kentros C, Moreno H, Franzen L, Hillman D, Baker H, Rudy B (1994) Differential expression of Shawrelated $\mathrm{K}+$ channels in the rat central nervous system. J Neurosci 14:949-972.

Weiser M, Bueno E, Sekirnjak C, Martone ME, Baker H, Hillman D, Chen S, Thornhill W, Ellisman M, Rudy B (1995) The potassium channel subunit Kv3.1b is localized to somatic and axonal membranes of specific populations of CNS neurons. J Neurosci 15:4298-4314.

Yin TCT, Chan JCK (1990) Interaural time sensitivity in the medial superior olive of the cat. J Neurophysiol 64:465-488.

Young SR, Rubel EW (1983) Frequency-specific projections of individual neurons in chick brainstem auditory nuclei. J Neurosci 7:1373-1378. 